\title{
Anomalous origin of the left coronary artery from pulmonary artery: Takeuchi operation
}

\section{Origem anômala de artéria coronária da artéria pulmonar: operação de Takeuchi}

\author{
Ulisses Alexandre CROTI, Domingo Marcolino BRAILE, Cristiane DE RESENDE, Lilian BEANI
}

RBCCV 44205-859

\section{CLINICAL DATA}

The case of a male 6-month-old breastfeeding Caucasian baby weighing $7.785 \mathrm{~kg}$ is reported. The baby was born by c-section weighing $3.28 \mathrm{~kg}$ after 40 weeks of gestation. At four months, the infant started with a bronchiolitis-type condition associated with tiredness, paleness, coughing and dyspnea during breastfeeding. The patient was consulted and congestive heart failure was diagnosed with referral to our service for further investigation. At admittance the patient was in a good general state, ruddy, hydrated, dyspneic, acyanotic and afebrile. The thorax was symmetrical, ictus cordis in the left $5^{\text {th }}$ intercostal space on the hemiclavicular line. The heartbeat was regular with two clicks at 120 beats per minute and without murmurs. Pulmonary auscultation was symmetrical without adventitious noises. The abdomen was flaccid with the liver $2 \mathrm{~cm}$ from the right costal border. The limbs had palpable and symmetrical pulses with differences in pressure between limbs. The patient was taking furosemide, spironolacton and digoxin.

\section{ELECTROCARDIOGRAM}

The electrocardiogram demonstrated sinus rhythm with a heartbeat of $120 \mathrm{bpm}$. The QRS angle was $-30^{\circ}$. There was a diffuse alteration of ventricular depolarization without

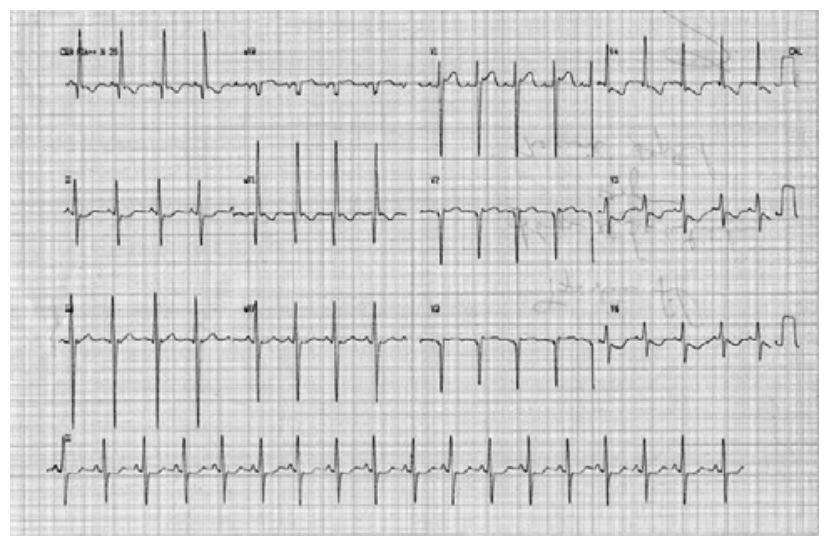

Fig. 1 - Electrocardiogram demonstrating the characteristics of the anomalous origin of the coronary artery from the pulmonary artery

ventricular overload and an inactive area in the high lateral region (Figure 1).

\section{RADIOGRAM}

A radiogram showed visceral situs solitus with a cardiac index of 0.64 with the left ventricle (LV) affected. The pulmonary fields had a slightly enlarged vascular network. The diaphragmatic domes were free. 


\section{ECHOCARDIOGRAM}

An echocardiogram showed a significant increase in the diameter of the LV with major contractile dysfunction. With Doppler, a turbulent flow was identified in the left atrium compatible with slight mitral valve insufficiency; the ejection fraction measured using the Simpson method was 33\%. The left coronary artery trunk measured $2.3 \mathrm{~mm}$ and originated from the left lateral region of the pulmonary artery (PA) with a flow in the opposite direction, that is, the coronary artery to the PA. The right coronary artery was dilated with a diameter of $3.8 \mathrm{~mm}$ with several collateral branches to the left coronary artery. There was an area of hyper-refringency in the LV, endocardium and the antero-lateral papillary muscle.

\section{DIAGNOSIS}

The echocardiogram is sufficient for an adequate diagnosis however this disease can evolve to mitral valve insufficiency, ventricular ischemia and the formation of an aneurysm. The electrocardiogram results together with the clinical examination are suggestive of the diagnosis with a fair amount of certainty however echocardiography identifies and defines the anatomy, determining the size and position of the anomalous coronary artery. When there is doubt as to the diagnosis, a selective coronary arteriography and/or magnetic resonance should be performed.

\section{OPERATION}

A median transsternal thoracotomy was followed by the establishing of cardiopulmonary bypass at $28^{\circ} \mathrm{C}$. Hypothermic anterograde sanguineous cardioplegia was utilized intermittently at 15-minute intervals directly into the coronary ostia. The PA was opened and a crosswise flap was removed from the anterior wall. Aortopulmonary openings of $4 \mathrm{~mm}^{2}$ were made in the left lateral wall of the aorta and the right lateral wall of the PA (Figure 2), and the two orifices were sutured. The flap was anastomised to the posterior wall of the pulmonary artery to the root of the anomalous coronary artery. Polydioxanone threads were utilized as these sutures allow growth. The operation was completed with a bovine pericardium patch sutured with polypropylene thread to the anterior wall of the PA with the aim of preventing obstruction [1]. The perfusion time was 104 minutes and the myocardial ischemic time was 77 minutes. Thus, the blood flow of the aorta passes through the aortopulmonary window, between the flap and the posterior wall of the PA to the root of the anomalous coronary artery, a result that is easily seen by echocardiography as illustrated in Figure 3 obtained in the $5^{\text {th }}$ postoperative month with a significant improvement in the ventricular ventilation and the created tunnel having excellent blood flow.

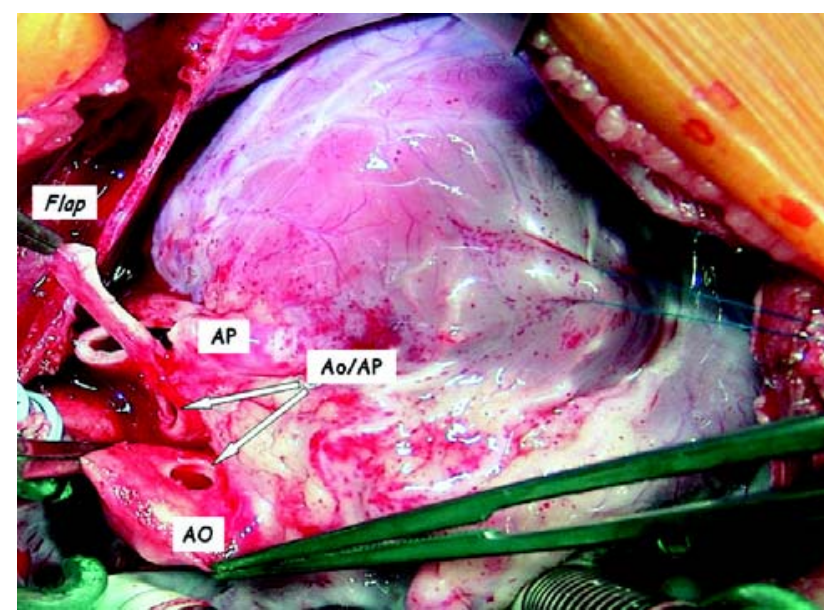

Fig. 2 - Inter-operative appearance with the flap of the pulmonary artery sectioned crosswise to create the tunnel. AO - aorta, APpulmonary artery, AO/AP - orifices in the aortic and pulmonary artery walls to form the aortopulmonary window

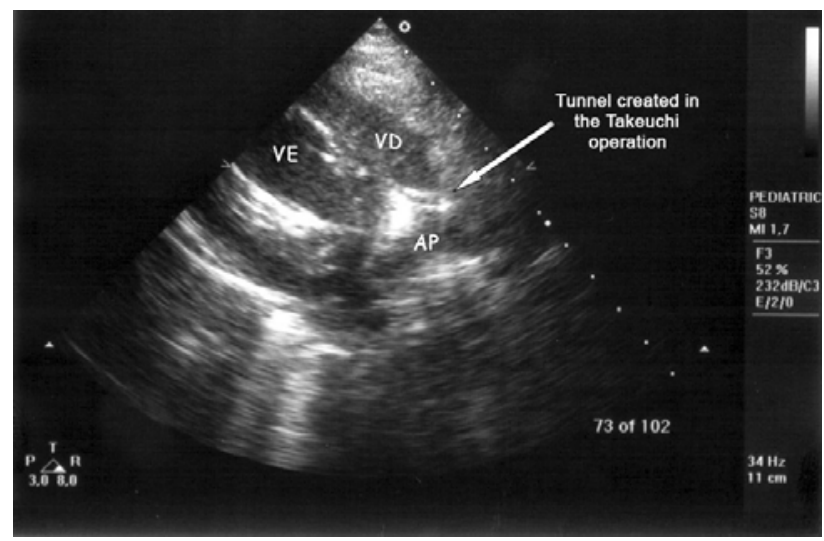

Fig. 3 - Echocardiogram in the 5th postoperative month with excellent flow from the aorta to the anomalous left coronary artery. $V E$ - left ventricle, $V D$ - right ventricle, $A P$ - pulmonary artery

\section{REFERENCES}

1. Takeuchi S, Imamura H, Katsumoto K, Hayashi I, Katohgi T, Yozu R, et al. New surgical method for repair of anomalous left coronary artery from pulmonary artery. J Thorac Cardiovasc Surg. 1979;78(1):7-11. 